\title{
Prenatal Histological Development of the Nephron in Goat Foetus (Capra hircus)
}

\author{
Tanvi Mahajan ${ }^{1 *}$, Kamal Sarma $^{1}$ and Jonali Devi ${ }^{2}$ \\ ${ }^{1}$ Division of Veterinary Anatomy, ${ }^{2}$ Division of Veterinary Physiology and Biochemistry, \\ Sher-e-Kashmir University of Agricultural Sciences \& Technology, Jammu, India
}

*Corresponding author

\section{A B S T R A C T}

\begin{tabular}{l}
\hline Key w or d s \\
$\begin{array}{l}\text { Histology, Nephron, } \\
\text { Goat, Prenatal, } \\
\text { Development }\end{array}$ \\
\hline Article Info \\
\hline $\begin{array}{l}\text { Accepted: } \\
\text { 15 January } 2021 \\
\text { Available Online: } \\
\text { 10 February 2021 }\end{array}$ \\
\hline
\end{tabular}

This study was conducted on the kidneys of 18 goat foetii divided into three age groups with six number of foetii in each group. At 45 days of gestation $(\mathrm{CRL}=5.3 \mathrm{~cm})$, cord like differentiating mesenchymal cells near the capsule were observed and at few places, they were arranged in clusters. The mesenchymal cells in some areas of the cortex, aggregated as nephrogenic vesicles. A vesicle at one of the end of a dividing ampulla grew into a double walled S-shaped body. At 48 days of gestation $(C R L=7.5 \mathrm{~cm})$, the kidney (metanephros) showed differentiating nephrogenic vesicles. At 50 days of gestation $(\mathrm{CRL}=7.6 \mathrm{~cm})$, formation of the nephrogenic vesicles and their elongation into $\mathrm{S}$-shaped structures increased in all the three zones of the cortex. The Bowman's capsule was nearly spheroidal in shape and numerous angioblasts were identified at this age. In the foetus of 50 days gestational age $(\mathrm{CRL}=7.6 \mathrm{~cm})$, the afferent arterioles were lined by differentiating elongated mesenchymal cells, which would be future juxtaglomerular cells. At 50 days of gestation $(\mathrm{CRL}=7.60 \mathrm{~cm})$, some cells which were the forerunners of the macula densa were noticed. At 62 days $(\mathrm{CRL}=10.10 \mathrm{~cm})$ of foetal age, true juxta glomerular cells were noticed.

\section{Introduction}

Kidneys are the main organs of urinary system which are responsible for regulation of fluid volume, acid base balance and electrolyte composition (Banks 1993). The development of kidney is a complicated process in all the mammals as it develops into pronephros, mesonephros and metanephros (Balinsky 1970; Dyce et al., 1987; Latshaw 1987). The pronephros and mesonephros degenerated during prenatal life but the metanephros forms in lumbar region and remains on the functional kidney in adults. The development of metanephros started from ureteric bud and nephrogenic blastema during prenatal life (Balinsky, 1970; Carlson, 1985; Latshaw, 1987). The development of metanephros in animals follows an accelerated time course when compared with the human (Canfield 1980). In ungulates, it becomes functional at an early embryonic age due to low permeability of placenta. Paucity of available literature on the histological 
development of the nephron of the metanephros in goat foetus prompted this present study.

\section{Materials and Methods}

The present study was conducted on 22 goat foetii which were collected from the slaughter houses in and around Jammu city. These foetii were ranged from early pregnancy to near full term. Immediately after collection, the umbilical cords of these foetii were ligated properly and were cleaned with cotton soaked with water to remove the amniotic fluid. The weight of each foetus was recorded with the help of analytical balance. The approximate age of the foetii were calculated by putting the body weight values in the formula postulated by Singh et al., (1979) for estimation of age in goat foetii as mentioned below-

Formula for estimation of foetal age in goat (Singh et al., 1979).

$\mathrm{W}^{1 / 3}=0.096(\mathrm{t}-30)$.

Where, $\mathrm{W}=$ body weight of foetus in $\mathrm{gm}$.

$\mathrm{t}=$ age of the foetus in days.

The collected foetii were then divided into three groups based on their estimated ages viz.- Group I (below 50 days), Group II (between 50 to 100 days) and Group III (above 100 days of age), each group containing at least 6 number of foetii in each group. After estimation of age, the kidneys were used for the histological and histochemical studies. The kidneys were fixed in 10\% Neutral Buffered Formalin solution (Luna 1968). The tissue pieces from the kidneys were processed for paraffin block preparation by alcohol-benzene schedule (Luna 1968). Tissue sections of 5-6 $\mu \mathrm{m}$ thickness were obtained from these blocks on clean glass slides with the help of rotary microtome and subsequently subjected to staining with various histological methods viz. Haematoxylin \& Eosin, Masson's Trichrome Stain/Verhoeff's stain, Hart's Stain, Gomori's Stain and Bielschowsky's method.

\section{Results and Discussion}

At 45 days of gestation $(\mathrm{CRL}=5.3 \mathrm{~cm})$, the differentiating mesenchymal cells near the capsule were observed having cord like arrangement and at few places, they were arranged in clusters. The mesenchymal cells in some areas of the cortex, aggregated as nephrogenic vesicles. This is in agreement with Onarlioglu et al., (1997) that observed no developed glomeruli in the kidneys where dense mesenchymal tissue take place in early stage of development in rat foetus. A vesicle at one of the end of a dividing ampulla grew into a double walled S-shaped body (Fig. 1) consisted of lower cup shaped and upper tubular segments. The cells lining both these segments were elongated with hardly visible cellular outline. The cytoplasm of these cells was sparse and chromophobic.

At 48 days of gestation $(\mathrm{CRL}=7.5 \mathrm{~cm})$, the kidney (metanephros) showed nephrogenic vesicles in different stages of development. The nephrogenic vesicles lengthened in the juxta medullary zone of the cortex and many of them changed into S- shaped anlage of the nephron. Their lower cup shaped ends were crescenteric and housed at places mesenchymatous elements as forerunners of renal glomeruli (Fig. 2). The latter was however, avascular and consisted of irregular shaped cells. A virtual space existed in almost all developing corpuscles between the parietal and visceral layers which might be referred to as the future Bowman's capsule. The Bowman's capsule of juxtamedullary region enclosed a glomerular mass of mesenchymal cells and occasional angioblasts. Vernier and 
Birch-Anderson (1962) described that immature glomeruli in human foetii developed as epithelial cell masses enclosed by parietal and visceral layer of Bowman's capsule. Lewis (1958) opined that the glomeruli in sheep take origin by the proliferation of visceral layer of Bowman's capsule into the enclosed mass of angioblastic cells. Mullinik (1971) stated that in dog, the capillaries and reticular fibres of the glomerulus developed by the ingrowth of the interstitial tissue. The upper tubular segment of the S-shaped vesicle of the juxta medullary zone differentiated into the proximal and distal tubules at this age. The proximal convoluted tubules were lined by simple columnar epithelium. Their rounded vesicular nuclei occupied the broad basal half of the cells (Fig. 3). The finely granular cytoplasm of these tubular cells stained deeply with Eosin. Double nucleoli could often be seen among their course chromatin granules. The luminal brush border however, could not be seen at this age (Fig. 3). The distal convoluted tubules were lined by cuboidal epithelium. The centrally placed nuclei of these cells appeared close to each other as compared to those of the proximal segment. Their nuclei were smaller than those of the proximal tubules.

\section{Fig}

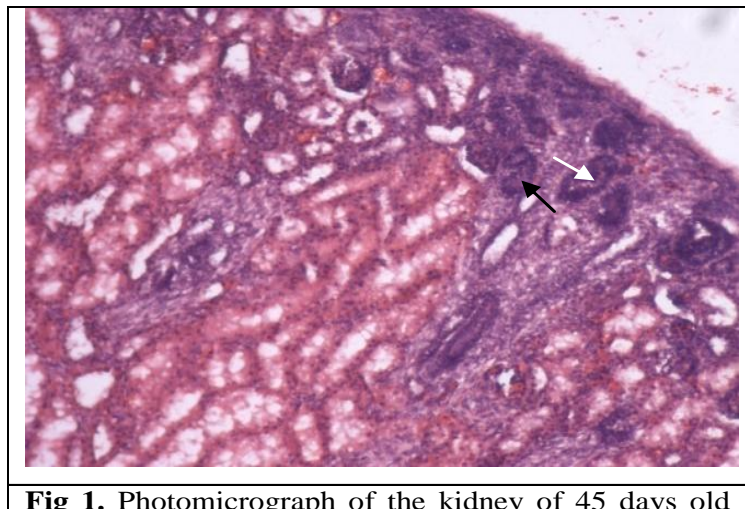

Fig 1. Photomicrograph of the kidney of 45 days old goat foetus showing $\mathrm{S}$-shaped bodies (arrows), H\&E, $100 \mathrm{X}$.

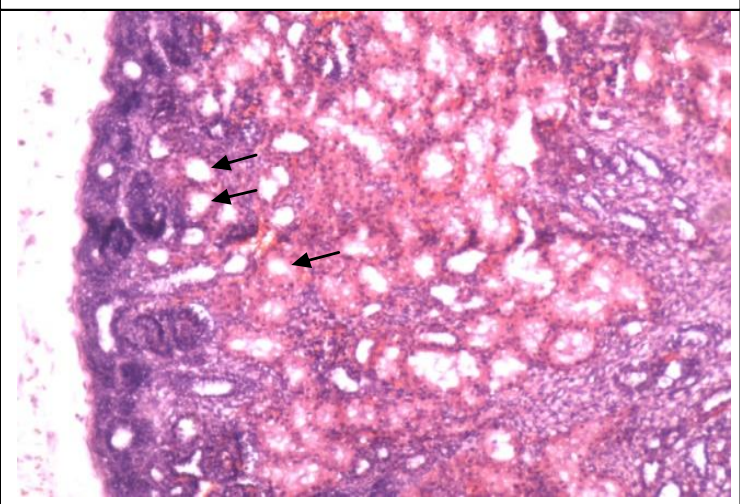

Fig 3. Photomicrograph of the kidney of 48 days old goat foetus showing developing proximal and distal convoluted tubules (arrows), H\&E, 100X.

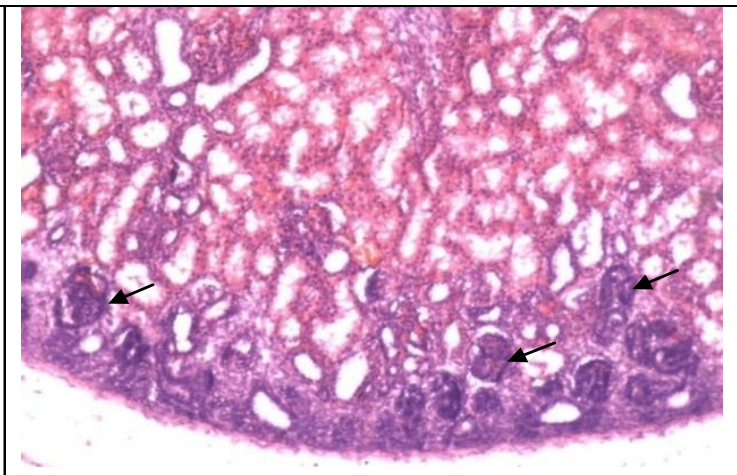

Fig 2. Photomicrograph of the kidney of 48 days old goat foetus showing developing renal glomeruli (arrows), H\&E, 100X.

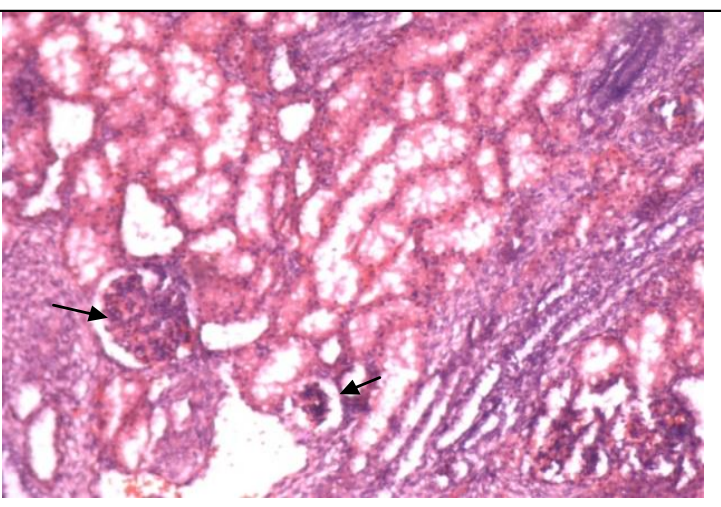

Fig 4. Photomicrograph of the kidney of 50 days old goat foetus showing potential Bowman's space of the renal corpuscles (arrows), H\&E, 100X . 


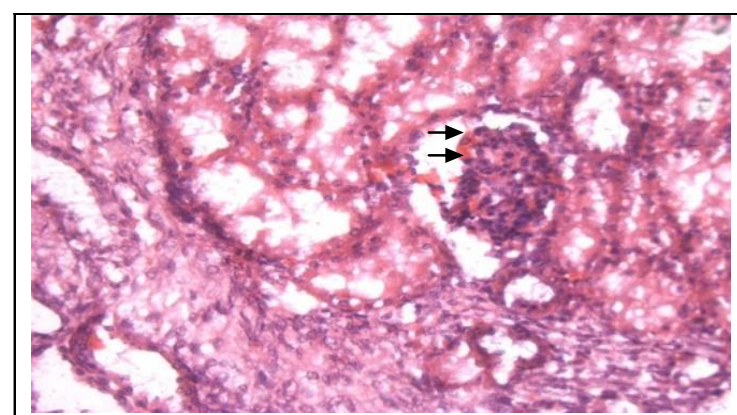

Fig 5. Photomicrograph of the kidney of 50 days old goat foetus showing angioblast cells in a developing glomerulus (arrows), H\&E, 200X.

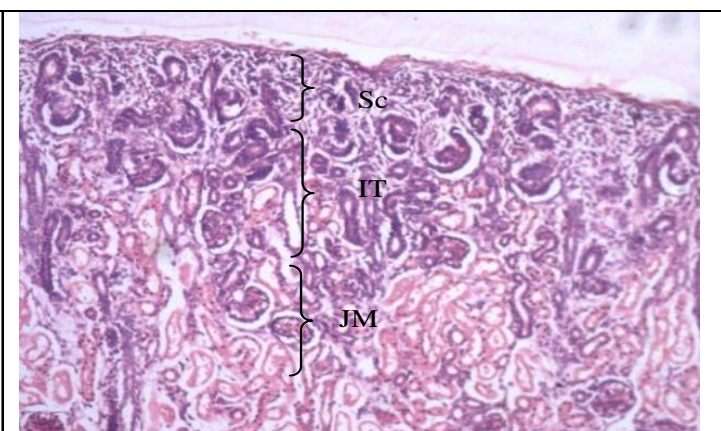

Fig 6. Photomicrograph of the kidney of 59 days old goat foetus showing subcapsular (Sc), Intermediate (IT) and juxta medullary regions (JM), H\&E, 100X.

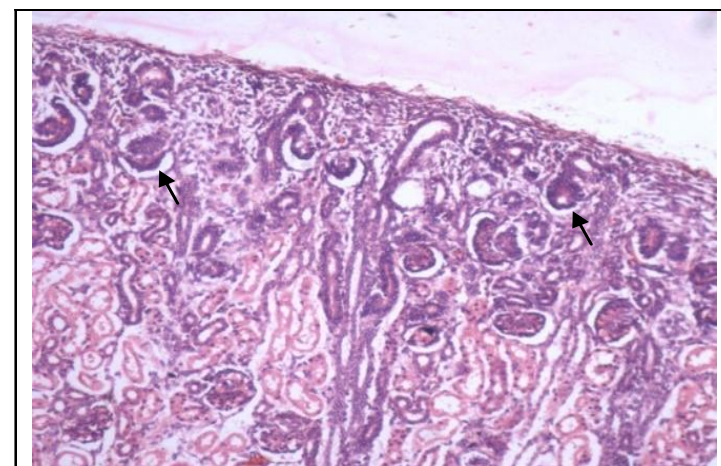

Fig 7. Photomicrograph of the kidney of 62 days old goat foetus showing spherical shaped glomeruli (arrows), H\&E, 100X.

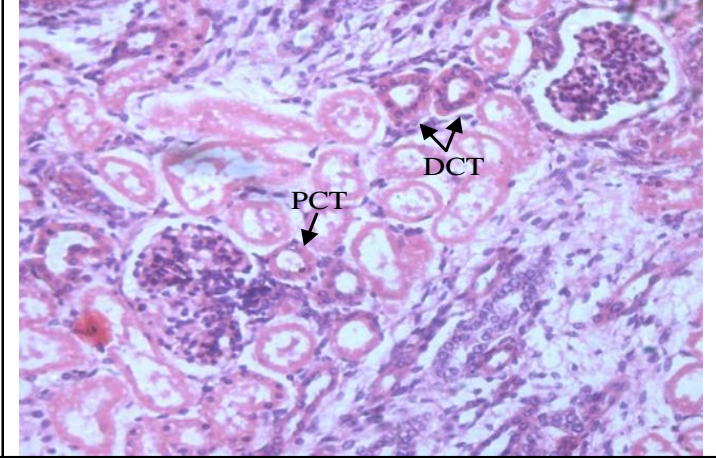

Fig 8. Photomicrograph of the kidney of 80 days old goat foetus showing proximal (PCT) and distal (DCT) convoluted tubules, H\&E, 200X.

Fig.9 Photomicrograph of the kidney of 135 days old goat foetus showing brush borders (arrows) in the proximal convoluted tubules, H\&E, 200X

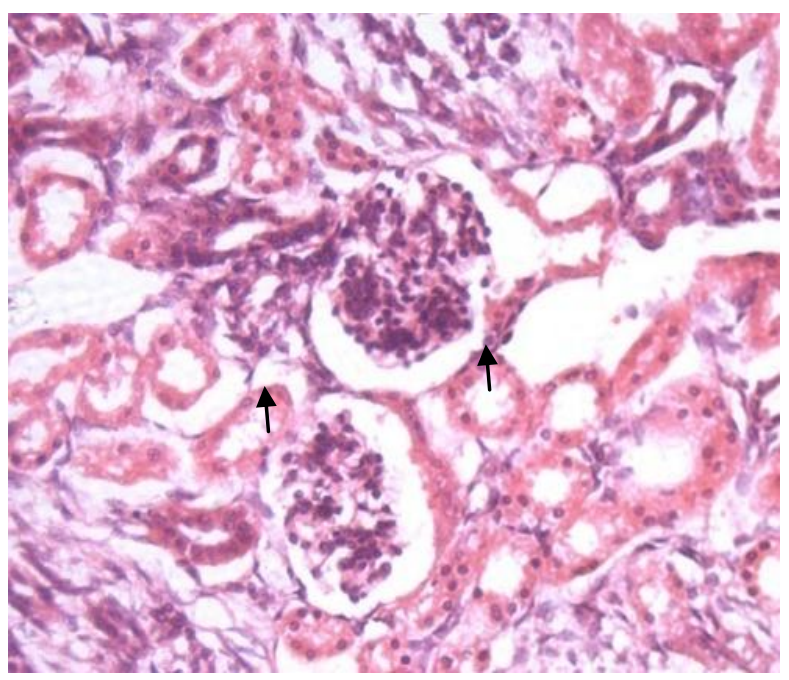


At 50 days of gestation $(\mathrm{CRL}=7.6 \mathrm{~cm})$, formation of the nephrogenic vesicles and their elongation into S-shaped structures increased in all the three zones of the cortex i.e. subcapsular, intermediate and juxta medullary zones. Similar observations were made in goat embryos at 58 days of gestation (Chaudhary et al., 2002). The lower cup shaped end of these structures was crescentric with a potential Bowman's space between the outer and inner epithelial walls (Fig. 4). Jokelainen (1963) stated that the cells which gave rise to Bowman's capsule and the epithelial portion of the glomeruli were different entities. The ingrowing of mesenchymal cells gave rise to glomerular capillaries. The renal corpuscles of the juxta medullary region advanced further in development. The Bowman's capsule was nearly spheroidal in shape (Fig. 4). The space between the parietal and visceral layers of epithelium increased in depth due to change of cells of the parietal layer into squamous. The glomerular mass of mesenchymal cells showed numerous angioblasts as identified by their highly chromatic nuclei and eosinophilic cytoplasm (Fig. 5). No fine capillary vessel was seen entering the juxta medullary glomeruli. At this age, the proximal and distal convoluted tubules increased in length and established communication with the adjacent arched collecting tubules. Potter (1965) identified capillary vessels invading the space between middle and lower limbs of S-shaped body.

\section{Group-II}

At 59 days $(\mathrm{CRL}=8.10 \mathrm{~cm})$ of gestation, the renal corpuscles of the subcapsular region were although crescentric in shape, the same in the juxta medullary region of the kidney (metanephros) resembled those of the mature kidney in shape and structure. The tubular segments of grown up nephrons in all the three zones (Fig. 6) showed division into proximal convoluted tubule, loop of Henle and distal convoluted tubule. Similar observations were made in goat embryos at 58 days of gestation (Chaudhary et al., 2002). The ascending and descending loops of Henle could not be differentiated histologically from the proximal and distal convoluted tubules at this stage. The thick ascending limb of loop of Henle was demonstrated at the age of $23.0 \mathrm{~cm}$ CVRL. Similar findings were reported by Gopinath (1985) and Chaudhary et al., (2002) in goat embryos. The middle thin segment of the loop of Henle was laid in the renal medulla between the collecting ducts. This segment was lined with simple squamous epithelium with ovoid to flattened nuclei bulging into the lumen. It was similar to the earlier reports of Gopinath (1985) in goat embryos. At 62 days $(\mathrm{CRL}=10.10 \mathrm{~cm})$ of gestation, the Bowman's capsule was spherical and enclosed a potential space between the parietal and visceral layers (Fig. 7). The afferent arteriole entered the glomeruli and split the mesengial mass into small cell groups by increasing capillary tufts with advancement of developmental process.

At 80 days of gestation $(\mathrm{CRL}=16.3 \mathrm{~cm})$, the renal corpuscles of similar structure were seen throughout the cortex of the kidney (metanephros) (Fig. 7). However, the juxta medullary glomeruli were larger as compared to those of subcapsular and intermediate zones. Lewis (1958) described origin of renal glomeruli in sheep by proliferation of visceral layer of Bowman's capsule into the enclosed mass of angioblastic cells, whereas, Mullinik (1971) observed their development in dog by in-growth of interstitial mesenchyme into the Bowman's capsule. The visceral layer of the Bowman's capsule was well organized and formed a continuous layer. The basement membranes of the parietal and visceral layers of the Bowman's capsule and the capillary tufts were formed of reticular fibres. All the renal corpuscle contained vascular glomeruli 
at this stage. The proximal convoluted tubules were lined with simple columnar epithelium. Their finely granular cytoplasm at all stages of development was deeply eosinophilic. Their nuclei were rounded. At this age, some of the differentiating proximal convoluted tubules contained 2-3 layers of cells with a clear lumen located just beneath the capsule. The luminal border of these cells was highly eosinophilic and nuclear chromatin was evenly distributed and densely stained. Some of the tubules were still in the process of canalization. However, some of the tubules possessed single layer of epithelial cells. The loop of Henle and its various constituents resembled histologically to the proximal and distal convoluted tubules. These were lined with simple cuboidal epithelium at all the developmental stages and these cells lacked brush borders at their apical surface. The thin middle segment of the loop of Henle was lined with flattened or low cuboidal epithelium. The distal convoluted tubules at all the developmental stages were lined with simple cuboidal epithelium. Their sparsely granulated cytoplasm stained always lightly with eosin as compared to that of the proximal convoluted tubules. The rounded nuclei of the epithelial cells occupied more or less a central position. Again, the nuclei of two adjacent cells were more close to each other than those of the proximal convoluted tubules (Fig. 8). At 84 days $(\mathrm{CRL}=17.30 \mathrm{~cm})$ and 94 days $(C R L=20.60 \mathrm{~cm})$ of gestation, the histological characteristics of the renal corpuscles were similar to the previous stages. Some of the distal convoluted tubules were still in the process of canalization and possessed 1-2 layers of cells.

\section{Group-III}

The epithelium of the proximal convoluted tubules rested on a distinct basement membrane. At 135 days of gestation $(\mathrm{CRL}=32.90 \mathrm{~cm})$, a distinct brush border was observed at the apical border of the lining columnar cells of the proximal convoluted tubules (Fig. 9). These tubules were lined by simple columnar epithelium in the foetii of $4.1 \mathrm{~cm}$ and $5.7 \mathrm{~cm}$ CVRL. The formation of microvilli at the luminal end of the epithelial cells was first formed at the age of $11.2 \mathrm{~cm}$ CVRL. The coiling of PCT also appeared at this age. In the foetii of $23.0 \mathrm{~cm}$ CVRL, these tubules were lined by simple cuboidal to pyramidal type of cells along with microvilli, which indicated its reabsorptive and secretory activities as reported in goat embryos by Gopinath (1985), Chaudhary et al., (2002) and Onarlioglu et al., (1997).

\section{References}

Balinsky, B. J. 1970. An Introduction to Embryology, W.B. Saunders Company, Philadelphia, Toronto and London. $3^{\text {rd }}$ Edition. pp: 450-452.

Banks, W. J. 1993. Applied Veterinary Histology, Mosby Year book, St. Louis, USA. $4^{\text {th }}$ Edition. pp: $374-389$.

Canfield, P. J. 1980. Development of the Bovine Metanephros. Anatomia Histologia Embryologia 9: 97-107.

Carlson, B. M. 1985. Patten's Foundation of Embryology, Tata Mc Graw Hill Publishing Company Ltd. New York. $4^{\text {th }}$ Edition. pp: 445-578.

Chaudhary, A. R., Farooqui, M. M. and Chandra, P. 2002. Histological and certain histochemical studies on the metanephros of goat (Capra hircus) in prenatal period-secretory part. Indian Journal of Veterinary Anatomy 14: 815.

Dyce, K. M., Sack, W. O. and Wensing, C. J. G. 1987. Textbook of Veterinary Anatomy, W B Sunders Company, Philadelphia, USA. pp: 162-167.

Gopinath, S. 1985. Morphogenesis of the kidney in goat. Ph.D. Thesis, Haryana Agricultural University, Hisar, India. 
Jokelainen, P. 1963. An electron microscopic study of the early development of the rat metanephric nephron. Acta Anatomica 47: 1-71.

Latshaw, W. K. 1987. Veterinary Developmental Anatomy-A Clinically Oriented Approach Blackwell Scientific Publication Ltd. Oxford, England.

Lewis, O. J. 1958. Development of blood vessels of metanephros. Journal of Anatomy 92: 84-97.

Luna, L. G. 1968. Manual of Histological Staining Methods of Armed Forces Institute of Pathology, McGrew Hill Book, Co. New York. $3^{\text {rd }}$ Edition. pp: 153-173.

Mullnik, J. W. M. A. 1971. Development of renal glomerulus in dogs. Veterinary Bulletin 41: 708.

Onarlioglu, B., Gursoy, E. and Kaloglu, C. 1997. Renal morphogenesis of rat foetus. Turkish Journal of Animal Science 21: 493-496.

Potter, E. L. 1965. Development of the human glomerulus. Archives of Pathology 80: 241-255.

Singh, Y., Sharma, D. N. and Dhingra, L. D. 1979. Morphogenesis of the testis in goats. Indian Journal of Animal Sciences 49: 925-931.

Vernier, R. L. and Birch-Anderson, A. 1962. Studies of the human foetal kidney. Journal of Pediatrics 60: 754-768.

\section{How to cite this article:}

Tanvi Mahajan, Kamal Sarma and Jonali Devi. 2021. Prenatal Histological Development of the Nephron in Goat Foetus (Capra hircus). Int.J.Curr.Microbiol.App.Sci. 10(02): 1493-1499. doi: https://doi.org/10.20546/ijcmas.2021.1002.178 